\title{
Comparison of Hand Hygiene Attitudes and Hand Swab Cultures in the Mothers of Children with Heart Disease Before and After Cardiac Surgery
}

\author{
Aysu Türkmen Karaağaç ${ }^{1}$ \\ ${ }^{1}$ Department of Pediatrics, Kartal Koşuyolu Research and Training \\ Hospital, University of Health Sciences, Istanbul, Turkey \\ J Child Sci 2017;7:e27-e31.
}

\begin{abstract}
Address for correspondence Aysu Türkmen Karaağaç, MD, Department of Pediatrics, Kartal Koşuyolu Research and Training Hospital, University of Health Sciences, Istanbul, Turkey (e-mail: aysukaraagac@gmail.com).
\end{abstract}

\begin{abstract}
Nosocomial infections ( $\mathrm{NI}$ ) carry high risk of morbidity and mortality especially for children undergoing surgeries. Hand hygiene $(\mathrm{HH})$ is the most effective and economic measure of $\mathrm{NI}$ control. This study was designed to compare the HH practices (HHPs), maternal anxiety scores (MASs), and hand swab cultures (HSCs) in the mothers of children with heart disease before and after cardiovascular surgery (CVS) to determine the factors that raised maternal HH sensitivity for prevention of NI. This prospective study included 120 mothers (age: 20-45 years; mean: $31.6 \pm 5.6$ years), whose children underwent CVS in the Kartal Koşuyolu Research and Training Hospital, University of Health Sciences between November 2016 and February 2017. HHP of each mother was assessed by a questionnaire, 10 questions in two parts and $\mathrm{HH}$ score (HHS) was acquired. Then, HSC was obtained. Beck anxiety inventory was applied to determine MAS. The relations among demographic characteristics, MAS, HSC results, and pre-/postoperative HHS of the mothers were compared statistically. There was a

\section{Keywords}

- cardiovascular surgery

- children

- hand hygiene

- heart disease

- mother

- swab culture significant increase in the HHS of the mothers in the postoperative period. Cronbach's a coefficient of the questionnaire was 0.84 . Maternal HHS was significantly correlated with maternal age $(p=0.001)$, education $(p=0.002)$, and MAS $(p=0.001)$, but not with the income $(\mathrm{p}=0.2)$. Moreover, one mother in the postoperative period $(0.8 \%)$ versus five mothers in the preoperative (4.2\%) had positive HSC. High education level, advanced age, and severe anxiety experienced by the mothers in their children's perioperative period were found to be the main factors that have raised maternal HHS, thereby resulting in better HSC results.
\end{abstract}

\section{Introduction}

Nosocomial lower respiratory tract, gastrointestinal, and blood stream infections caused by Staphylococcus aureus, Klebsiella pneumonia, and Clostridium difficile in the pediatric patients undergoing cardiovascular surgery (CVS) are mainly transmitted by disseminated hands of caregivers. ${ }^{1,2}$ Hand washing is an effective, easy, and economical measure to prevent transmission of these microorganisms. ${ }^{3}$ There are

received

April 29, 2017

accepted after revision

June 7, 2017
DOI https://doi.org/

10.1055/s-0037-1604263. ISSN 2474-5871. three types of hand washing: social hand washing with solid or liquid soap and water for removal of dirt; hygienic hand washing with medicated soap, and the hygienic hand disinfection with alcohol-based hand rub without water. ${ }^{3,4}$ As the immune systems of children are highly vulnerable to the assaults of microorganisms, especially after major surgical interventions, and the mothers are their main caregivers, maternal hand hygiene (HH) practices (HHPs) should always be promoted. This study was performed to assess the HHPs in

Copyright $\odot 2017$ Georg Thieme Verlag License terms KG Stuttgart · New York 
the mothers of children with congenital heart disease (CHD) before and after CVS and to define the factors that promote maternal $\mathrm{HH}$ compliance.

\section{Materials and Methods}

In this prospective cohort study, 120 mothers, whose children underwent CVS in the Kartal Koşuyolu Research and Training Hospital, University of Health Sciences between November 2016 and February 2017 were enrolled. Children with CHD are routinely internalized 1 week before the CVS for preoperative evaluation in our hospital. They are transferred from the pediatric CVS intensive care unit (PCVS-ICU) to the pediatric ward as soon as they become ready for the mother care. The questionnaires about the HHPs of the mothers and the Beck anxiety inventory (BAI) ${ }^{5}$ to define the level of anxiety they experienced during their children's perioperative period were applied to each mother face to face. A 10-minute HH training was given about the definition, appropriate technique, and importance of hand washing. Then, hand swab culture (HSC) of the mother was obtained. These procedures were applied twice, on the second day of hospitalization of the child for surgery and on the second day of his/her transfer from the PCVS-ICU to the pediatric ward. Two mothers whose children died in the PCVS-ICU were excluded from the study. The questionnaire was composed of 10 questions in two parts: first part being about the demographic properties of the mothers (age, education, and economical status) and second part about their $\mathrm{HH}$ behaviors (frequency of hand washing, hand washing before and after nourishing the child, cleaning the home, sneezing, or coughing). The answers in the second part were scaled; 0 point was given for "never," 1 point for "rarely," 2 points for "sometimes," 3 points for "frequently," 4 points for "usually," and 5 points for "always." The HHS of each mother was calculated by adding their scores. BAI presents a list of common symptoms of anxiety. ${ }^{5}$ Mothers were requested to indicate how much they have been bothered by each symptom. While scoring, 0 point was given for "not at all," 1 point for "mildly-it did not bother me much," 2 points for "moderatelyit was not pleasant at times," and 3 points for "severely-it bothered me a lot" answers. The maternal anxiety score (MAS) was calculated by finding the sum of 21 items. Score of 0 to 21 was accepted as "low anxiety," 22 to 35 "moderate anxiety," and a score of 36 and above as "high levels of anxiety."

\section{Microbiological Analysis}

HSCs of the mothers were obtained by rubbing the sterile cotton swab wetted by $0.9 \% \mathrm{NaCl}$ solution, to the palms, back of the hands, fingers, and bottom of the rings of the mothers, as soon as the questionnaires were completed, without allowing them to wash their hands. Then, these swab cultures were immediately transferred to the microbiology laboratory and plated on to blood and MacConkey's agars. If there is any microbial growth after 24 to 48 hours of incubation at $37^{\circ} \mathrm{C}$, Gram staining was performed to decide whether it was gram positive or negative. If it was gram positive, coagulase test was applied. VITECR2 automated microbial identification system was used to identify the gram-negative bacteria. Then, the antibiotic susceptibility testing was performed by disc diffusion method according to the Clinical and Laboratory Standards Institute (CLSI) criteria. ${ }^{6}$ Written consent of the mothers was received. Study was approved by University of Health Sciences, Kartal Koşuyolu Research and Training Hospital Ethic Committee.

\section{Statistical Analysis}

Continuous variables were expressed as mean \pm standard deviation and categorical variables as counts and percentages. Statistical analysis was performed by statistical package for the social sciences (SPSS Inc, Chicago, Illinois, United States), 15.0 version. Descriptive analysis was performed to evaluate the demographic data. The reliability analysis of the questionnaire was performed and the Cronbach's $\alpha$ coefficient was calculated. Demographic characteristics were cross-tabulated against HHPs of the mothers. Categorical variables were analyzed by using chi-square/Fisher's exact test. Continuous variables were analyzed by paired samples $t$-test and Wilcoxon signed-ranks test. A $p$-value of $<0.05$ was accepted as statistically significant.

\section{Results}

All mothers included in the study replied the questionnaires in the pre- and postoperative periods. The mean age of the mothers was $31.6 \pm 5.6$ years (20-45 years). Sixty percent of these mothers had left education at the elementary school level and $9.7 \%$ of them were illiterate. When grouped according to the economical status, $48.3 \%$ of the mothers were in the middle income group with a monthly income of 1,000 to 5,000 Turkish liras (-Table $\mathbf{1}$ ).

The final Cronbach's $\alpha$ coefficient was calculated as 0.84 , indicating a high degree of internal reliability of the questionnaire. There was a significant increase in the ratio of

Table 1 Demographic characteristics of the mothers enrolled in the study

\begin{tabular}{|l|l|l|l|}
\hline $\begin{array}{l}\text { Demographic } \\
\text { characteristics }\end{array}$ & $\begin{array}{l}\text { Number } \\
(\boldsymbol{n}=\mathbf{1 2 0})\end{array}$ & $\begin{array}{l}\text { Ratio } \\
(\%)\end{array}$ & $95 \% \mathrm{Cl}$ \\
\hline Age of the mothers (y) & 49 & 40.8 & $39.2-42.4$ \\
\hline $20-29$ & 46 & 38.3 & $36.9-39.6$ \\
\hline $30-39$ & 25 & 20.9 & $18.9-22.9$ \\
\hline$\geq 40$ & 11 & 9.7 & $7.9-11.5$ \\
\hline Level of education & 72 & 60.0 & $59.3-60.7$ \\
\hline Illiterate & 26.6 & $25.6-27.6$ \\
\hline Elementary school & 72 & 4.7 & $2.1-6.3$ \\
\hline High school & 32 & & \\
\hline University & 5 & 41.7 & $40.8-42.5$ \\
\hline Monthly income (TL) & \multicolumn{5}{|l|}{} \\
\hline$\leq 1,000$ & 50 & 48.3 & $47.7-49.07$ \\
\hline $1,000-5,000$ & 58 & 10.0 & $8.3-11.7$ \\
\hline$\geq 5000$ & 12 &
\end{tabular}

Abbreviations: $\mathrm{Cl}$, confidence interval; TL, Turkish liras. 
Table 2 Comparison of hand washing frequencies of the mothers in the pre- and postoperative periods

\begin{tabular}{|l|l|l|l|}
\hline $\begin{array}{l}\text { Hand washing } \\
\text { frequency }\end{array}$ & $\begin{array}{l}\text { Preoperative } \\
\text { period } \\
\boldsymbol{n}(\%)\end{array}$ & $\begin{array}{l}\text { Postoperative } \\
\text { period } \\
\boldsymbol{n}(\%)\end{array}$ & \multirow{2}{*}{0.001} \\
\hline$\leq 5$ times & $4(3.4)$ & $1(0.8)$ & \\
\hline $5-10$ times & $19(15.8)$ & $7(5.9)$ & \\
\hline$\geq 10$ times & $97(80.8)$ & $112(93.3)$ & \\
\hline
\end{tabular}

${ }^{a} p$-Value $<0.05$ was accepted as statistically significant.

mothers who reported washing hands 10 times or more daily in the postoperative period $(n=112,93.3 \%$ postoperative period vs. $n=97,80.8 \%$ preoperative), as shown in - Table 2 . The replies of the mothers to the questions about their HHPs after several HH requiring activities are shown in - Table 3. There was a significant rise in the HHS of the mothers in the postoperative period ( $p=0.001$ ). The ratios of "always" hand washing behaviors are shown in - Fig. 1. Of the 120 participants, 92 (76.7\%) were using only liquid soap as the hand washing material in the preoperative period and the number of mothers using liquid soap and disinfectant solution increased from 0 to 18 (15\%) in the postoperative period, which was statistically significant $(p=0.002)$. Moreover, a positive correlation was found among the age, education, and maternal HHS in the pre- and postoperative periods ( $p=0.001$ and $p=0.002$, respectively). However, there was no correlation between the income and maternal HHS $(p=0.2)$ ( - Table 4). According to the BAI results, the mean MASs of the mothers were $34.1 \pm 2.1$ versus $36.8 \pm 1.9$ points in the pre- and postoperative periods. A positive correlation was found between the mean MAS and the HHS of the mothers $(p=0.001)$. There were five positive HSCs $(4.2 \%)$ in the preoperative (one obtained from the fingertips, two from the palms, and two under the rings) and one (0.8\%) in the postoperative (obtained from the palm) period.

Table 3 Assessment of hand hygiene attitudes of the mothers in the pre- and postoperative periods

\begin{tabular}{|c|c|c|c|c|c|c|c|c|c|c|}
\hline \multirow{2}{*}{$\begin{array}{l}\text { Questions } \\
\text { Hand hygiene attitudes } \\
\text { of the mothers }\end{array}$} & \multicolumn{5}{|c|}{$\begin{array}{l}\text { Preoperative period } \\
n=120 \\
(\%)\end{array}$} & \multicolumn{5}{|c|}{$\begin{array}{l}\text { Postoperative period } \\
n=120 \\
(\%)\end{array}$} \\
\hline & Never & Rarely & Sometimes & Frequently & Always & Never & Rarely & Sometimes & Frequently & Always \\
\hline $\begin{array}{l}\text { Washing hands before and } \\
\text { after feeding the child }\end{array}$ & 0 & 0 & $\begin{array}{l}14 \\
(11.7)\end{array}$ & $\begin{array}{l}21 \\
(17.5)\end{array}$ & $\begin{array}{l}85 \\
(70.8)\end{array}$ & 0 & 0 & $\begin{array}{l}2 \\
(1.7)\end{array}$ & $\begin{array}{l}24 \\
(20)\end{array}$ & $\begin{array}{l}94 \\
(78.3)\end{array}$ \\
\hline $\begin{array}{l}\text { Washing hands after changing the } \\
\text { diaper or helping child in toilet }\end{array}$ & 0 & 0 & 0 & $\begin{array}{l}18 \\
(15)\end{array}$ & $\begin{array}{l}102 \\
(85)\end{array}$ & 0 & 0 & 0 & $\begin{array}{l}8 \\
(6.6)\end{array}$ & $\begin{array}{l}112 \\
(93.4)\end{array}$ \\
\hline Washing hands after self-toilet use & 0 & 0 & 0 & $\begin{array}{l}15 \\
(12.5)\end{array}$ & $\begin{array}{l}105 \\
(87.5)\end{array}$ & 0 & 0 & 0 & $\begin{array}{l}4 \\
(3.3)\end{array}$ & $\begin{array}{l}116 \\
(96.7)\end{array}$ \\
\hline $\begin{array}{l}\text { Washing hands after sneezing } \\
\text { or nose cleaning }\end{array}$ & 0 & $\begin{array}{l}7 \\
(5.8)\end{array}$ & $\begin{array}{l}14 \\
(11.6)\end{array}$ & $\begin{array}{l}29 \\
(24.2)\end{array}$ & $\begin{array}{l}70 \\
(58.4)\end{array}$ & 0 & 0 & $\begin{array}{l}10 \\
(8.3)\end{array}$ & $\begin{array}{l}28 \\
(23.3)\end{array}$ & $\begin{array}{l}82 \\
(68.4)\end{array}$ \\
\hline $\begin{array}{l}\text { Washing hands after cleaning } \\
\text { sink and floor }\end{array}$ & 0 & 0 & $\begin{array}{l}4 \\
(3.3)\end{array}$ & $\begin{array}{l}24 \\
(20)\end{array}$ & $\begin{array}{l}92 \\
(76.7)\end{array}$ & 0 & 0 & $\begin{array}{l}2 \\
(1.6)\end{array}$ & $\begin{array}{l}20 \\
(16.7)\end{array}$ & $\begin{array}{l}98 \\
(81.7)\end{array}$ \\
\hline
\end{tabular}

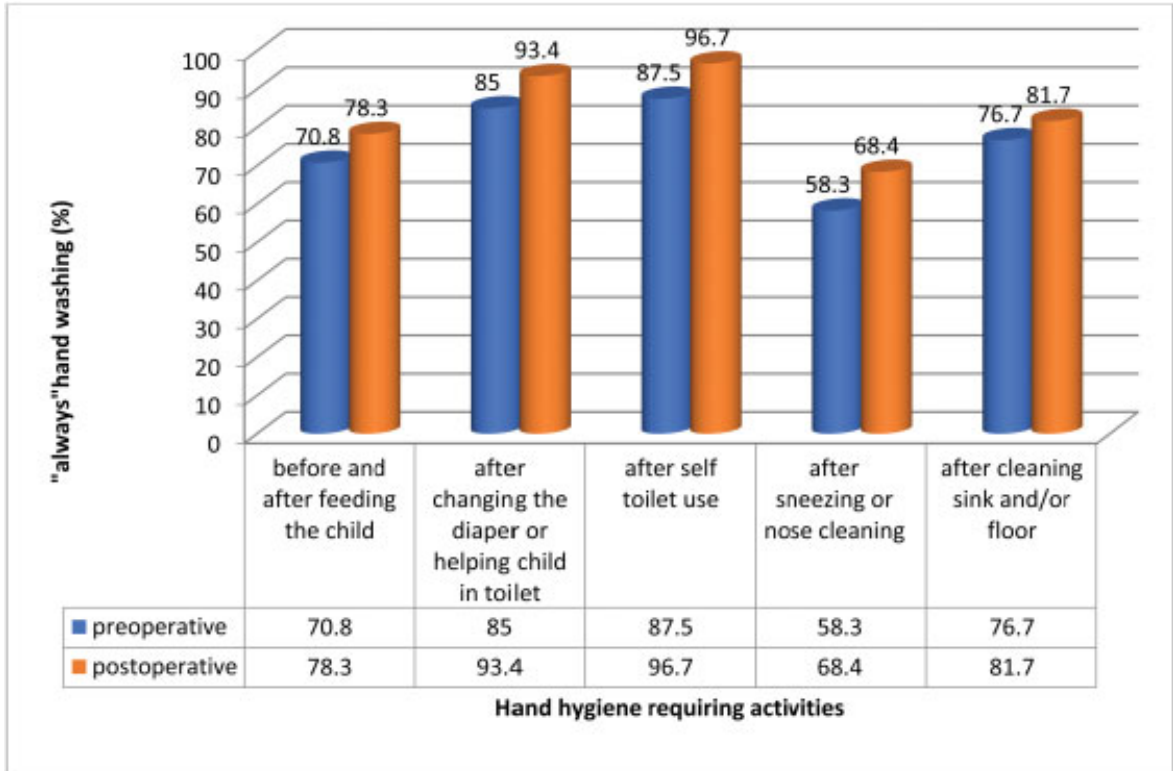

Fig. 1 Comparison of the mothers "always" hand washing ratios after hand hygiene requiring activities in the pre- and postoperative periods. 
Table 4 Comparison of HHSs of the mothers with respect to their demographic properties in the pre- and postoperative periods

\begin{tabular}{|c|c|c|c|c|}
\hline $\begin{array}{l}\text { Demographic properties } \\
\text { of the mothers }\end{array}$ & $\begin{array}{l}\text { Preoperative HHS } \\
(\text { mean } \pm \text { SD) }\end{array}$ & $p$-Value ${ }^{a}$ & $\begin{array}{l}\text { Postoperative } \mathrm{HHS}^{\mathrm{b}} \\
(\text { mean } \pm \text { SD) }\end{array}$ & $p$-Value ${ }^{\mathrm{b}}$ \\
\hline \multicolumn{5}{|l|}{ Maternal age $(\mathrm{y})$} \\
\hline $20-29$ & $18.3 \pm 1.7$ & \multirow[t]{3}{*}{0.001} & $20.2 \pm 1.2$ & \multirow[t]{3}{*}{0.001} \\
\hline $30-39$ & $20.2 \pm 1.4$ & & $22.8 \pm 1.3$ & \\
\hline$\geq 40$ & $23.0 \pm 1.5$ & & $24.6 \pm 1.1$ & \\
\hline \multicolumn{5}{|l|}{ Educational level } \\
\hline Illiterate & $18.5 \pm 1.3$ & \multirow[t]{4}{*}{0.002} & $21.6 \pm 1.6$ & \multirow[t]{4}{*}{0.001} \\
\hline Elementary school & $20.9 \pm 1.7$ & & $22.8 \pm 1.4$ & \\
\hline High school & $23.2 \pm 1.6$ & & $24.5 \pm 1.6$ & \\
\hline University & $24.8 \pm 0.7$ & & $24.9 \pm 0.5$ & \\
\hline \multicolumn{5}{|l|}{ Monthly income (TL) } \\
\hline$\leq 1,000$ & $22.6 \pm 1.5$ & \multirow[t]{3}{*}{0.2} & $23.7 \pm 1.3$ & \multirow[t]{3}{*}{0.3} \\
\hline $1,000-5,000$ & $24.5 \pm 1.1$ & & $24.7 \pm 1.2$ & \\
\hline$\geq 5,000$ & $24.8 \pm 0.8$ & & $24.9 \pm 0.8$ & \\
\hline
\end{tabular}

Abbreviations: HHS, hand hygiene score; SD, standard deviation; TL, Turkish liras.

${ }^{a} p$-Value $<0.05$ statistically significant.

${ }^{\mathrm{b}}$ Postoperative period.

Microorganisms isolated from these cultures were coagulase-negative staphylococci, Escherichia coli, and Enterobacter $\mathrm{sp}$. As the HHSs of the mothers were increased, a statistically significant decrease was found in their HSC positivity in the postoperative period $(p=0.001)$.

\section{Discussion}

Hand washing is accepted as the most effective, economical, and the easiest infection control measure all over the world. ${ }^{7,8}$ World Health Organization reported that $45 \%$ of gastrointestinal and 10 to $44 \%$ of respiratory tract infections could be prevented just by improved HHPs. ${ }^{9}$ This study showed that HHPs of the mothers, main caregivers of the pediatric patients after the pediatric staff in pediatric wards, were mainly affected by age, education level, and the anxiety they experienced in the peroperative period. Limited studies about $\mathrm{HH}$ applications of mothers have shown that $65.3 \%$ of the mothers, in the study by Mech and Ojah, ${ }^{10}$ and $96 \%$ of the mothers, in the study by Pati et al, ${ }^{11}$ were aware about the importance of hand washing with soap for infection control. Jabbar et al reported that hand washing with soap and water was significantly more effective at removing $C$. difficile spores from the hands of volunteers than alcohol-based hand rubs. $^{12}$ In the present study, $80.8 \%$ of the mothers in the preoperative period and $93.3 \%$ in the postoperative period have reported that they were washing hands 10 times or more in a day. Moreover, $76.7 \%$ of them were using liquid and $17.5 \%$ were using solid soap for hand washing in the preoperative period. In the postoperative period, a statistically nonsignificant decrease was observed in liquid and solid soap use, but the ratio of the mothers who began to use disinfectant gel or solutions in addition to the liquid soap showed a statistically significant increase. This could be due to the efforts, application of questionnaires, HH trainings, and anxiety scoring that raised their awareness about the importance of HH. Ray et al reported low hand washing compliances in the mothers after cleaning the home (39\%), before feeding their children (38\%), and before cooking $(35 \%){ }^{13}$ In the present study, a statistically significant increase was found in the "always" hand washing frequencies and HHS of the mothers after hygiene requiring activities in the postoperative period. Although there is a sink, liquid soap and disinfectant solution in each room, and the mothers have no difficulty in reaching hand washing materials in our pediatric ward, their HHSs showed a statistically significant increase after their children had CVS. Wray and Sensky ${ }^{14}$ and Utens et $\mathrm{al}^{15}$ showed in their studies that the mothers become extremely stressful when their children undergo surgery, especially CVS, and that their anxiety scores increase with age and education. In the present study, the scores obtained from BAI showed that the mothers had very high level of anxiety in the peroperative period. A positive correlation was found between the MAS and the HHS of the mothers. Moreover, a statistically significant relationship was found among the age, educational status of the mothers, and their HHSs; however, the relationship between the income and the HHS was insignificant in both pre- and postoperative periods. Shen et al presented that mostly gram-positive bacteria, coagulase-negative staphylococci as the major pathogens, were isolated from hand rub cultures of the participants in both pre- and postoperative periods. ${ }^{16}$ Some studies showed that $C$. difficile was colonized mainly in the subungual area (43\%), on the fingertips (37\%), on the palms (37\%), and under rings $(20 \%)$ of the hands. ${ }^{17,18}$ Moreover, it was shown that Acinetobacter species could survive $>150$ minutes and $E$. coli 60 to 90 minutes on the hand surfaces. Therefore, these microorganisms are 
highly contagious. ${ }^{19-21}$ In this study, 5 out of 120 hand rub cultures $(4.2 \%)$ were positive, coagulase-negative staphylococci, E. coli, and Enterobacter sp. being the major pathogens ( 1 isolated from the fingertips, 2 from the palms, and 2 from under the rings) in the preoperative period and only 1 culture $(0.8 \%)$ was positive (E. coli obtained from the palm) in the postoperative period.

\section{Limitations of the Study}

As this is a single-center study performed in a tertiary CVS hospital, the study population is very selective and the results may not represent the whole Turkish mothers. Another limitation of this study was that as the majority of the mothers were illiterate or elementary school graduated and the questionnaires were performed face to face, they might have exaggerated the answers due to social embarrassment.

\section{Conclusion}

HHPs of the mothers in this study were acceptable in the preoperative period, but they were significantly improved after their children underwent cardiac surgery. Advanced age, high education level, and increased anxiety were the main determinants of this improvement. Further studies should be conducted to confirm the findings of this study and to explore new HHA improvement strategies targeting the mothers and pediatric staff for better nosocomial infection control.

\section{Conflict of interest}

None.

\section{References}

1 Grisaru-Soen G, Paret G, Yahav D, Boyko V, Lerner-Geva L. Nosocomial infections in pediatric cardiovascular surgery patients: a 4-year survey. Pediatr Crit Care Med 2009;10(02):202-206

2 Dixit D, Hagtvedt R, Reay T, Ballermann M, Forgie S. Attitudes and beliefs about hand hygiene among paediatric residents: a qualitative study. BMJ Open 2012;2(06):e002188

3 Martínez JA, Pozo L, Almela M, et al. Microbial and clinical determinants of time-to-positivity in patients with bacteraemia. Clin Microbiol Infect 2007;13(07):709-716

4 Stover BH, Shulman ST, Bratcher DF, Brady MT, Levine GL, Jarvis WR; Pediatric Prevention Network. Nosocomial infection rates in US children's hospitals' neonatal and pediatric intensive care units. Am J Infect Control 2001;29(03):152-157

5 Beck AT, Epstein N, Brown G, Steer RA. An inventory for measuring clinical anxiety: psychometric properties. J Consult Clin Psychol 1988;56(06):893-897
6 Performance Standards for Antimicrobial Susceptibility Testing: Twenty-third Informational Supplement. Clin Lab Stand Inst 2015;33(01):100-123

7 Limper HM, Barton G, McGinty M, et al. Behavioral intention of physician trainees and medical students to practice hand hygiene. Infect Control Hosp Epidemiol 2013;34(10):1102-1105

8 Magill SS, Edwards JR, Bamberg W, et al; Emerging Infections Program Healthcare-Associated Infections and Antimicrobial Use Prevalence Survey Team. Multistate point-prevalence survey of health care-associated infections. N Engl J Med 2014;370(13): 1198-1208

9 World Health Organization (WHO)/The United Nations Children's Fund (UNICEF). Global Action Plan for Prevention and Control of Pneumonia (GAPP). World Health Organization/The United Nations Children's Fund (UNICEF); 2009

10 Mech K, Ojah J. A study on the awareness and practices of hand washing amongst mothers of under-five children in the slums of Guwahati city. J Evid Based Med Health 2016;3(24): 1075-1078

11 Pati S, Kadam SS, Chauhan AS. Hand hygiene behavior among urban slum children and their care takers in Odisha, India. J Prev Med Hyg 2014;55(02):65-68

12 Jabbar U, Leischner J, Kasper D, et al. Effectiveness of alcoholbased hand rubs for removal of Clostridium difficile spores from hands. Infect Control Hosp Epidemiol 2010;31(06):565-570

13 Ray SK, Zaman FA, Laskar NB. Hand washing practices in two communities of two states of Eastern India: an intervention study. Indian J Public Health 2010;54(03):126-130

14 Wray J, Sensky T. Psychological functioning in parents of children undergoing elective cardiac surgery. Cardiol Young 2004;14(02): 131-139

15 Utens EM, Versluis-Den Bieman HJ, Verhulst FC, Witsenburg M, Bogers AJ, Hess J. Psychological distress and styles of coping in parents of children awaiting elective cardiac surgery. Cardiol Young 2000;10(03):239-244

16 Shen NJ, Pan SC, Sheng WH, et al. Comparative antimicrobial efficacy of alcohol-based hand rub and conventional surgical scrub in a medical center. J Microbiol Immunol Infect 2015;48 (03):322-328

17 Pineles LL, Morgan DJ, Limper HM, et al. Accuracy of a radiofrequency identification (RFID) badge system to monitor hand hygiene behavior during routine clinical activities. Am J Infect Control 2014;42(02):144-147

18 Miller MA, Hyland M, Ofner-Agostini M, Gourdeau M, Ishak M; Canadian Hospital Epidemiology Committee. Canadian Nosocomial Infection Surveillance Program. Morbidity, mortality, and healthcare burden of nosocomial Clostridium difficile-associated diarrhea in Canadian hospitals. Infect Control Hosp Epidemiol 2002;23(03):137-140

19 Kampf G, Kramer A. Epidemiologic background of hand hygiene and evaluation of the most important agents for scrubs and rubs. Clin Microbiol Rev 2004;17(04):863-893

20 McLaws ML, Taylor PC. The Hospital Infection Standardised Surveillance (HISS) programme: analysis of a two-year pilot. J Hosp Infect 2003;53(04):259-267

21 Kim JM, Park ES, Jeong JS, et al; Nosocomial Infection Surveillance Committee of the Korean Society for Nosocomial Infection Control. Multicenter surveillance study for nosocomial infections in major hospitals in Korea. Am J Infect Control 2000;28(06):454-458 